\title{
Моделирование рассеяния бесселевых пучков малыми частищами с помощью метода дискретных диполей
}

\author{
С.А. Глухова \\ Институт химической кинетики и горения СО РАН \\ Новосибирский государственный университет \\ E-mail: stefgluhova@gmail.com
}

DOI: 10.31868/RFL2020.219-220

Бесселевы пучки (БП), принадлежащие к классу недифрагирующих пучков, набирают все большую популярность в таких областях, как микроскопия, манипулирование частицами (наиболее известное применение - оптический пинцет), лазерная обработка материалов, квантовая обработка информации, нелинейная спектроскопия [1,2]. Хотя рассеяние этих пучков частицами простой формы, такими как шар или сфероид, уже рассматривалось в литературе, для сложных частиц такое рассеяние моделируется редко. Метод дискретных диполей (МДД) является численно точным методом моделирования рассеяния и поглощения электромагнитных волн частицами произвольной формы и внутренней структуры [3]. Данный метод основан на объемной дискретизации интегральных уравнений Максвелла в частотной области. В общем, МДД и соответствующий компьютерный код применимы для произвольных падающих полей. Однако, практическое моделирование для любых падающих пучков доступнее, если они встроены непосредственно в компьютерную программу. Таким образом, основной целью этой работы является реализация БП в программном пакете с отрытым кодом ADDA [4].

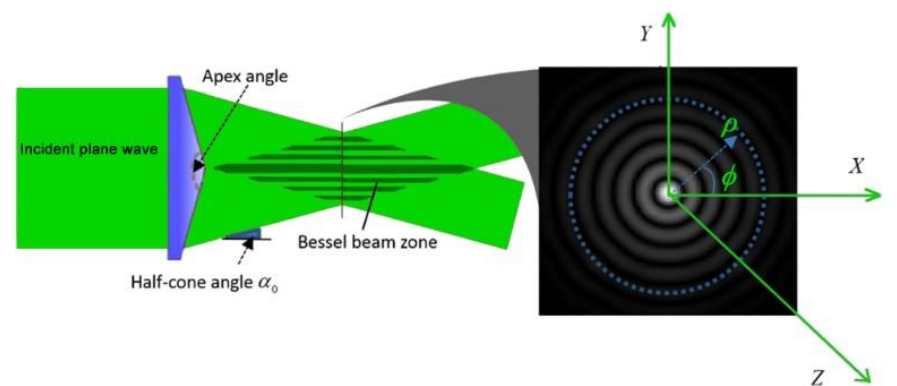

Рис. 1. Схема генерации бесселева пучка 0-го порядка с помощью конической линзы (аксикона) [5].

В данной работе формализм матриц Мюллера, используемый в большинстве методов и программ (включая ADDA), был расширен для всех типов БП. Для этого были определены две базисные поляризации для каждого типа БП, связанные друг с другом поворотом на угол $\pi / 2$, и дополнительным сдвигом фазы, возникающим ввиду вихревых свойств БП. Также, были введены новые типы БП, поляризации которых позволяют реализовать осесимметричные типы БП. Далее, соотношения вращения были обобщены для произвольного угла поворота. Таким образом, была расширена существующая классификация БП и их поляризаций с акцентом на поворотные соотношения между ними. Все выбранные типы БП были реализованы в ADDA. Результаты моделирования, полученные в данной работе, хорошо согласуются с эталонными результатами для обобщенной теории Лоренца-Ми. В итоге, теперь всем доступно 
моделирование рассеяния БП произвольными частицами, включая матрицы рассеяния.

\section{Литература}

[1] Wang J.J. et al. J. Quant. Spectrosc. Radiat. Transfer. Vol. 195. P. 8-17 (2017)

[2] Stoian R. et al. Advanced Optical Technologies. Vol. 7, № 3. P. 165-174. (2018)

[3] Yurkin M.A., Hoekstra A.G. J. Quant. Spectrosc. Radiat. Transfer. Vol. 106, № 1-3. P. 558-589. (2007)

[4] Yurkin M.A., Hoekstra A.G. J. Quant. Spectrosc. Radiat. Transfer. Vol. 112, № 13. P. 2234-2247. (2011)

[5] Wang J.J. et al. J. Quant. Spectrosc. Radiat. Transfer. Vol. 184. P. 218-232. (2016)

Научный руководитель - канд. физ.-мат. наук. М. А. Юркин. 